\title{
MIGRAÇÃO, PREVENÇÃO EM SAÚDE MENTAL E REDE DIGITAL
}

Sylvia Dantas ${ }^{1}$

\begin{abstract}
O propósito desse artigo é discutir o papel do atendimento e orientação psicológica intercultural para prevenção a saúde mental de imigrantes através da mediação da tecnologia. Baseia-se em pesquisa intervenção realizada em duas universidades brasileiras. Essa tecnologia demonstrou ser uma ferramenta de grande utilidade. Através de estudo de caso de brasileiros assistidos em nossas pesquisas indicamos que a tecnologia na mediação intercultural constitui, em termos psicanalíticos, um objeto transicional para quem se desloca de ambiente cultural. Apontamos, o importante papel da tecnologia como instrumento de prevenção na promoção do bem estar daqueles em mobilidade no mundo. Em um mundo em que paradoxalmente as tecnologias estão cada vez mais desenvolvidas sua utilização não raro tem gerado ou contribuído para o acirramento da desigualdade e cisão social, levando inclusive a crescentes demonstrações de preconceito e xenofobia. Indicamos aqui o uso da tecnologia na saúde mental como parte de medidas que garantam o direito humano a uma vida digna e de sentido onde quer que se esteja no mundo.
\end{abstract}

Palavras-chave: orientação intercultural, tecnologia, prevenção saúde mental.

O propósito desse artigo é discutir o papel do atendimento e orientação psicológica intercultural para prevenção a saúde mental de imigrantes através da mediação da tecnologia. Baseia-se em pesquisa intervenção realizada em duas universidades brasileiras. Apontamos o importante papel da tecnologia como instrumento de prevenção na promoção do bem estar daqueles em mobilidade no mundo. Através de estudo de caso de brasileiros assistidos em nossas pesquisas baseadas em intervenção psicossocial indicamos que a mediação

1 Universidade Federal de São Paulo - UNIFESP, Instituto Estudos Avançados, IEA-USP. Santos, SP, Brasil. 
intercultural através da tecnologia pode constituir um objeto transicional em termos psicanalíticos ${ }^{2}$ para aqueles que se deslocam.

Em um mundo em que paradoxalmente as tecnologias estão cada vez mais desenvolvidas sua utilização não raro tem gerado ou contribuído para o acirramento da desigualdade e cisão social ${ }^{3}$, levando inclusive a crescentes demonstrações de preconceito e xenofobia. Contudo, a tecnologia tem também trazido a possibilidade de troca e promoção de informações não veiculada pela mídia tradicional. Os meios de comunicação tradicionais apresentam-se muitas vezes tendenciosos no sentido de veicularem textos e imagens carregadas de ideias preconceituosas ou descontextualizadas. Paralelamente, ao lado disso, há o fortalecimento de redes de solidariedade, na contramão dos valores propagados pelo sistema mundial capitalista financeiro voltado para o propósito do aumento do lucro de corporações mundiais. Indicamos aqui o uso da tecnologia na prevenção à saúde mental como parte possível de ferramenta no fortalecimento aos direitos fundamentais a uma vida digna e de sentido onde quer que se esteja.

Faremos uma breve contextualização das migrações brasileiras, do uso da tecnologia pela psicologia, seguido de nosso embasamento teórico, sua inserção na saúde. A fim de ilustrar o que propomos apresentamos alguns casos clínicos com a articulação teórica mencionada e posteriormente considerações finais.

\section{E/imigração no mundo e no Brasil}

O crescimento do deslocamento de pessoas que cruzam fronteiras nacionais com o advento da tecnologia tem sido fator importante na configuração das sociedades atuais. A migração é considerada atualmente um dos temas definidores do mundo globalizado. Os modernos meios de transporte e de comunicação possibilitam que cada vez mais povos das mais diversas etnias e nacionalidades em diferentes localidades do mundo entrem em contato com grande rapidez.

Sabe-se que atualmente, por volta de 232 milhões de pessoas residem em país diferente daquele onde nasceram (OIM). Grosso modo, isto significa que uma a cada trinta e cinco pessoas no mundo é um migrante. Pessoas que também vivem a questão da migração em grande número são os filhos de migrantes que nascem nos países para onde seus pais mudaram ${ }^{4}$.

As motivações para os deslocamentos são diversas. Contudo, não podemos deixar de entender que a migração transnacional traz benefícios substanciais para o mundo industrializado, o fluxo de trabalhadores tem geralmente um bom nível educacional comparado à média nacional de seus países e estão dispostos a

\footnotetext{
2 WINNICOTT, Donald W. O Brincar e a Realidade.

3 BAUMAN, Zygmunt. Globalização: as conseqüências humanas.

4 SAM, David, BERRY John. The Cambridge Handbbok on Acculturation Psychology.
} 
preencher funções que estão vagas no país hospedeiro por serem pouco procuradas pelos nativos e com baixo custo. É importante lembrar que esta população, assim como outras minorias ${ }^{5}$, é muitas vezes usada como bode expiatório no país receptor, ou seja, como objeto de culpa no sistema social, sendo a ela atribuída a causa do desemprego e de outros problemas sociais. Casos de xenofobia em relação a imigrantes têm sido frequentes na história mundial. Com a emigração, alivia-se a pressão econômica e política dos países em desenvolvimento, muitos deixam o país e mandam remessas de dinheiro que ajudam a subsidiar um nível de vida de classe média aos que ficaram. O fenômeno da migração transnacional decorrente da globalização capitalista industrial afetou e afeta a vida de milhões de pessoas. Os possíveis desdobramentos dessas questões têm importantes implicações sociais, políticas, culturais assim como para o bem-estar psicológico dos indivíduos que compõem as respectivas nações envolvidas.

A mudança de país ocorre, portanto, dentre um contexto social, político e histórico que precisa ser compreendido a fim de que se possa entender como as representações coletivas dadas em determinada época atravessam a vida de cada indivíduo e estão interconectadas a motivações subjetivas daqueles que cruzam fronteiras culturais.

A imigração no Brasil pode-se dizer, começa com a colonização portuguesa e com a imigração forçada de populações escravizadas vindas da África. Nos últimos três séculos até 1850 por volta de 4 milhões de pessoas do continente africano foram trazidas para o Brasil para o trabalho escravo. Com a colonização portuguesa, as diversas nações indígenas que aqui residiam sofrem uma aculturação imposta. Ao término do período escravocrata, políticas governamentais atraem mão de obra imigrante. Sabe-se que entre 1872 a 1972, mais de 5 milhões de imigrantes entraram no Brasil, a maioria de Portugal e Itália, mas também da Espanha, Alemanha, Japão e países do Oriente Médio, entre outros. Apesar de apenas por volta de duzentos e quarenta mil japoneses terem imigrado para o Brasil, hoje os 1,5 milhões de nikkeis ${ }^{6}$ compõem a maior comunidade de japoneses e descendentes fora do próprio Japão.

Em meados dos anos oitenta ocorre no país um processo inverso ao da imigração, um fluxo de brasileiros emigram em busca de melhores condições de vida para terras alheias. Em 2008, o Ministério das Relações Exteriores (MRE) estimou mais de 3 milhões de brasileiros vivendo em 117 países nos quais há

Minoria no sentido de menor representatividade e poder político, pois em termos numéricos grupos denominados minoritários são muitas vezes maioria (como é o caso dos afro-descendentes no Brasil).

6 Nikkei é uma denominação em língua japonesa derivado do termo nikkeijin (nikkeijin) que se refere aos japoneses que emigraram do Japão e seus descendentes. O termo nikkei tem diferentes e múltiplos significados dependendo da situação, local e ambiente. Pode incluir os filhos de casamentos mistos que se autodenominam Nikkeis. No Japão o termo também é usado pelos nativos para designar os emigrantes que voltam para o país e seus descendentes (www.discovernikkei.org). 
representação diplomática brasileira ${ }^{7}$. Os Estados Unidos, o Japão, o Paraguai e a Europa foram os maiores receptores deste fluxo emigratório. Mas o Brasil entra na dinâmica da migração internacional não só como país de envio, mas também de recepção. A significativa imigração coreana, chinesa e boliviana vem somar-se à estimativa de um milhão de estrangeiros morando no Brasil. Há ainda, um contingente significativo que se encontra em situação irregular, não entrando assim nas estatísticas oficiais. O país também recebe refugiados, havendo atualmente em torno de 8.400 mil de 75 nacionalidades, além de 45.607 haitianos com residência permante com visto humanitário ${ }^{8}$.

Sabemos ser esse um processo dinâmico e em constante mudança. Assim, com a crise financeira mundial de 2008 o fenômeno da migração de retorno se acentua e muitos brasileiros que residiam no exterior voltam para o Brasil. Conforme o censo de 2010, havia na época 455.335 pessoas retornadas internacionais $^{9}$. Em seguida, com a crise financeira atingindo o Brasil por volta dessa época, assistimos a novas frentes, ainda não muito estudadas, de emigração e re-emigração de brasileiros novamente em busca de melhores condições de vida no exterior ${ }^{10}$.

\section{Um pouco sobre assistência psicológica através da tecnologia}

Segundo Pieta ${ }^{11}$ e Pieta e Comes ${ }^{12}$ estudos acerca da terapia via internet no Brasil são praticamente inexistentes. Conforme os autores explicam, há uma diferença entre psicoterapia online e psicoterapia baseada na internet. A psicoterapia online ou psicoterapia pela internet constitui uma terapia realizada pelo profissional por e-mail, chat, mensagem instantânea, áudio ou videoconferência, sem excluir a possibilidade de encontros presenciais. É desta que estaremos tratando no presente artigo. Já as intervenções baseadas na internet são programas computadorizados de terapia, com ou sem participação do terapeuta que incluem DVD, CDRom realidade virtual e feedback online. Um exemplo é uma intervenção que inclua textos e gráficos para transmitir informações, instruções de áudio para relaxamento progressivo, vídeo apresentando casos, suporte do terapeuta por e-mail, bem como envio de msg automática por e-mail ou lembretes por SMS. Esses programas computadorizados, que têm crescido especialmente na Austrália, são ferramentas de prevenção para pacientes em fila de espera, a fim de que

FUSCO, Wilson, SOUCHAUD, Sylvain. De volta para casa: a distribuição dos brasileiros retornados do exterior.

${ }^{8}$ MELLO, Patrícia Campos. Número de refugiados no Brasil quase dobra em quatro anos.

9 BOTEGA, Tuíla, CAVALCANTI, Leonardo, OLIVEIRA, Antônio Tadeu. Migrações Internacionais de Retorno no Brasil.

${ }^{10}$ NAKAGAWA, Fernando. Crise desperta desejo de migrar e brasileiros tentam emprego na Inglaterra e Japão.

11 PIETA, Maria Adélia M. Psicoterapia pela internet: a relação terapêutica.

12 PIETA, Maria Adélia M., GOMES, William B. Psicoterapia pela internet: Viável ou inviável? 
possam aprender sobre sintomas depressivos ou de ansiedade. Um exemplo é o MoodGym baseado na perspectiva teórica da psicologia da terapia cognitivo comportamental. Grande parte dos estudos internacionais volta-se para a efetividade das terapias cognitivo-comportamentais. Outras abordagens que vem sendo praticadas baseiam-se na perspectiva psicodinâmica e centrada na pessoa.

Estudos internacionais recentes revistos por aqueles autores mostram que a terapia online também pode ser promissora no tratamento das adições e jogo patológico, da psicose, no trabalho com refugiados e imigrantes, no caso de depressão em pacientes terminais e de deficientes auditivos. Além disso, não apenas adultos podem se beneficiar da psicoterapia pela Internet, mas também adolescentes e crianças. $\mathrm{O}$ anonimato pode auxiliar na busca de atendimento psicológico de pessoas introvertidas, com transtorno de ansiedade como agorafobia e fobia social, com problemas de imagem corporal, bem como adolescentes e usuários de substâncias.

As terapias online e intervenções baseadas na Internet variam em seu sincronismo. Podem envolver comunicação sincrônica, isto é, imediata (e.g. chat) ou assincrônica, ou seja, com algum atraso (e.g. e-mail), que pode ser curto (e.g. e-mail diário), ou longo (e.g. email de resposta do terapeuta a cada três dias). Na psicoterapia online via e-mail o terapeuta deve combinar intervalos determinados de resposta para não suscitar ansiedade no paciente. Nas intervenções baseadas na Internet, o sincronismo tanto pode ser predeterminado pelo programa, pelo software utilizado, como adaptado às necessidades do paciente. O tempo de duração entre as sessões também varia. Enquanto alguns programas prescrevem sessões semanais ou diárias, outros não determinam número de sessões, permitindo acesso não estruturado por um determinado período de tempo. Há programas que variam a frequência, podendo iniciar com uma alta frequência de sessões que, após um período crítico, diminuem. Igualmente o feedback varia em termos de quantidade, frequência e rapidez de resposta. O feedback humano tende a ser mais adaptado às circunstâncias do paciente em comparação ao automático.

\section{Abordagem Intercultural e Psicodinâmica}

Temos apresentado ${ }^{13}$ o enfoque intercultural como abordagem que promove uma visão ampla, dinâmica e flexível dos fenômenos psicossociais, e entende o desenvolvimento humano e suas manifestações decorrentes da relação dialética entre o sujeito e os contextos culturais e sociopolíticos. Sarriera ${ }^{14}$ explica que a área de ação da intervenção psicossocial se configura no complexo

${ }^{13}$ DANTAS, Sylvia. An intercultural psychodynamic counseling model. A preventive work proposition for plural societies.

${ }^{14}$ SARRIERA, José. Psicologia comunitária, estudos atuais. 
processo de interação sujeito-meio social e objetiva o bem-estar humano. No trabalho psicológico com migrantes, adotamos a técnica de psicoterapia breve ${ }^{15} \mathrm{e}$ orientação a partir de uma perspectiva intercultural psicodinâmica. Há dois eixos universais para classificar a psicoterapia intercultural.

O primeiro é o Emico-Ético, que de empréstimo dos estudos do linguista K.L.Pike são denominados de abordagem êmica e ética (de fonêmica e fonética). A abordagem êmica considera aspectos específicos de uma cultura, estuda-se o comportamento a partir do interior do sistema; examina-se uma cultura apenas; o analista descobre a estrutura; os critérios são relativos às características internas. A abordagem ética considera aspectos gerais, em que se estuda o comportamento de uma posição externa ao sistema; examinam-se mais culturas, comparando-as umas com as outras, a partir de um ético provisório aborda os êmicos culturais e deles deriva um novo ético mais abrangente, universal. O desafio para o terapeuta que se lança para além de seu milieu cultural é o peso que dará ao universal e ao culturalmente específico e como mudar de uma referência à outra ou como combinar ambas. Passos no sentido êmico levantam a questão da universalidade na psicoterapia no plano dos conceitos, técnicas, objetivos e valores. Daí a necessidade de voltarmo-nos para a direção ética, mas com uma base sólida e cientes de nossa inevitável formação cultural.

O outro eixo é o Autoplastic-Alloplastic. Todos nós respondemos a situações mudando a nós mesmos (autoplastic) ou ao ambiente (alloplastic) ou combinando estas duas operações em diferentes proporções. Até que ponto as psicoterapias ou aconselhamentos entre culturas não estão orientadas a mudar o indivíduo em detrimento ao ambiente? A possibilidade de estender o campo de ação do indivíduo no sentido de mudar o ambiente foi em grande parte negligenciada, favorecendo um objetivo implícito de um maior grau de conformismo direcionado ao indivíduo socialmente e culturalmente considerado desviante.

$\mathrm{Na}$ perspectiva intercultural o contexto é crucial, necessitamos compreender etnograficamente as culturas em contato, para entendermos o indivíduo. Daí constituir-se como uma área na psicologia ancorada em diversas disciplinas como a antropologia, demografia, economia, ciências políticas, sociologia e história. Conforme mencionamos em outros trabalhos ${ }^{16}$, a terapia e orientação intercultural são uma área emergente, notada por seu potencial e por ser um campo que desafia a considerar nossos pressupostos, valores, métodos como culturalmente limitados e, portanto sob suspeita.

Propomos assim, através de nossa experiência no trabalho de intervenção psicossocial, um novo modelo em que se utiliza a psicologia intercultural (Crosscultural Psychology), a qual pauta-se em grande parte nas teorias cognitivas, porém

${ }^{15}$ FIORINI, Hector. Teorias e técnicas de psicoterapias.

${ }^{16}$ DANTAS, Sylvia. Diálogos Interculturais: Reflexões interdisciplinares e intervenções psicossociais. 
de maneira ampliada, no sentido de articulá-la aos aspectos psicodinâmicos. Ou seja, trata-se de uma ampliação que entendemos ser parte da perspectiva intercultural no trabalho psicossocial e que vem ao encontro de novos paradigmas no trabalho psicoterápico ${ }^{17}$ que responde as novas demandas.

Realiza-se, portanto uma compreensão psicodinâmica do caso e de suas manifestações. Uma compreensão que abarca os processos de aculturação e suas dinâmicas transgeracionais, em que identificações estão sempre permeadas por representações culturais e de diferentes processos de aculturação daquele que nos procura e de suas figuras significativas. Cabe ao profissional de saúde estar atento e compreender esses entrelaçamentos conforme apresentamos em alguns estudos de caso $^{18}$.

A intervenção tem um caráter preventivo primário e secundário. Segundo Bleger ${ }^{19}$ na prevenção primária supomos a prevenção da doença, uma psicoprofilaxia que se define com o emprego de recursos psicológicos por parte de psicólogos para prevenir doenças (não só doenças mentais), sendo parte da saúde pública e instrumento de promoção da saúde. Já na prevenção secundária temos a partir do diagnóstico precoce a assistência voltada para a melhora. O termo breve dá a ideia muitas vezes de algo superficial, corriqueiro. No entanto, a psicoterapia breve se orienta fundamentalmente no sentido da compreensão psicodinâmica dos determinantes atuais da situação de enfermidade, crise ou descompensação e não omite a consideração dos fatores disposicionais históricos, mas dá ênfase à estrutura da situação transversal e às condições de vida daquele que busca auxílio.

A terapia breve constitui um enfoque que considera o paciente-pessoa como ser social, com uma ação recíproca dialética do interno e externo e vincula os problemas pessoais com os aspectos do mundo circundante. Supõe, conforme descrito por Fiorini ${ }^{20}$, uma postura terapêutica que vem ao encontro de características próprias de terapeutas culturalmente efetivos. Estas constituem: autoconhecimento, especialmente quanto ao que se considera como condutas adequadas e inadequadas na cultura; consciência das características gerais da terapia e sua relação com a cultura e classe social; habilidade de compartilhar da visão de mundo do cliente e não estar culturalmente encapsulado.

Cabe lembrar inclusive que toda concepção de saúde é culturalmente engendrada. Assim, não só temos diferentes visões de mundo que retratam formas distintas de compreensão do que é saúde como a partir destas. Cada cultura tem formas distintas de realizar a promoção da saúde, assim como de buscar a cura quando do que se considera adoecimento. Ainda sobre terapeutas culturalmente

\footnotetext{
${ }^{17}$ OSORIO, Luis Carlos. Novos paradigmas em psicoterapia.

${ }^{18}$ DANTAS, Sylvia. Nikkeis entre o Brasil e o Japão: desafios identitários, conflitos e estratégias.

19 BLEGER, Jose. Psico-higiene e psicologia institucional.

${ }^{20}$ FIORINI, op. cit.
} 
efetivos, supõe-se a compreensão das forças sócio-políticas que afetam os clientes, especialmente racismo e opressão; domínio eclético de técnicas e teorias, e capacidade de escolher qual é a mais apropriada para o cliente em particular. Nesse sentido, enfatizam-se as reações contratransferenciais que em geral este hiato engendra. O estar em sintonia com as emoções e sentimentos que o contato desperta. Portanto, do profissional nessa situação se requer o máximo de auto-percepção, não basta estar disposto a escutar e conhecer o outro, deve estar preparado para lidar com os desafios que estar entre culturas apresenta para o questionamento das concepções relativas ao próprio trabalho profissional. Estar entre culturas significa a possibilidade de novas formas e ressignificações do que antes se julgava certo. Como já ressaltado ${ }^{21}$ é fundamental que estejamos atentos ao perigoso equívoco de psicopatologizar a conduta daquele cujo sofrimento está vinculado ao deslocamento. Isto significa particularizar uma situação que é naturalmente geradora de estresse e de desconserto emocional. Não se considera o contexto, há uma desconexão entre o contexto social, cultural e político e o indivíduo. Algo que infelizmente vemos ainda ocorrer com profissionais que trabalham com migrantes e descendentes. Portes e Rumbaut ${ }^{22}$ mostram que isso ocorreu no início do século XX na América do Norte em relação aos imigrantes. Visão essa que foi posteriormente reformulada nos anos 1950, quando estudos sociológicos levaram em conta os conceitos de powerlessness, falta de controle sobre a própria vida e alienação, como fatores que geram graus de estresse e desordens mentais. Sabe-se que podem emergir estados depressivos suscetíveis de comportamentos suicidas, quando pensamentos de desvalia e achatamento do afeto são recorrentes, além de psicoses reativas, em que o contexto enlouquecedor leva a pessoa a realizar uma cisão do eu como forma de defesa em relação à realidade que é compreensivelmente incompreensível. Em todos esses casos é possível verificar a inter-relação entre global-local e saúde mental.

\section{Orientação Intercultural com uso da tecnologia}

Em uma universidade oferecemos orientação intercultural em que a internet foi primeiramente utilizada para divulgação do serviço através de um site e endereço eletrônico para contato, possibilitando o acesso ao serviço por parte de brasileiros residindo em diferentes regiões do Brasil assim como em outros países. Além dos atendimentos psicoterápicos individuais e grupais presenciais, realizamos também atendimentos e orientações com auxílio da internet. Em outra universidade continuamos a receber mensagens por email de brasileiros residindo no exterior sobre questões pontuais como dificuldades de relacionamento familiar (muitas vezes vinculadas a questões de gênero) ou questionamentos em como se preparar para o retorno para o Brasil.

${ }^{21}$ DANTAS, Diálogos Interculturais..., op. cit.

22 PORTES, Alejandro, RUMBAUT, Rubén. Immigrant America: A Portrait. 
Na primeira universidade foram realizados atendimentos em psicoterapia breve por meio do uso da tecnologia. Aos participantes foi enviada carta de consentimento informado que os mesmos assinaram e enviaram por correio à universidade. $\mathrm{O}$ trabalho foi realizado dentro dos parâmetros propostos pelo Conselho Federal de Psicologia (Resolução CFP 012/2005) em que atendimentos psicoterápicos online, considerados na época uma prática não reconhecida pela psicologia, eram permitidos quando parte de projeto de pesquisa. Retomo aqui dois casos atendidos, descritos em outra publicação ${ }^{23} \mathrm{a}$ fim de ilustrar esse procedimento e apresentar uma analise do lugar de sentido desse procedimento a partir dos conceitos psicanalíticos winnicottianos. Ambos os casos são de brasileiras que residem no exterior e entram em contato conosco através do endereço eletrônico divulgado no site no Serviço de Orientação Intercultural (na época na USP24) solicitando auxilio psicológico.

Marina residia no Japão e Andrea na Alemanha ${ }^{25}$. No primeiro caso, ao indagarmos Marina o que a levava a buscar o serviço naquele momento, ela relata estar tendo tonturas, labirintite, perda de audição, dificuldades visuais e muito sono. Já havia realizado vários exames de saúde e não havia sido constatada nenhuma anormalidade. Em função de falhas, na época do sistema da web, o atendimento se faz por telefone. Algo similar a um atendimento via web somente utilizando audição. No Japão, ela havia sido atendida por medico psiquiatra que lhe receitou relaxante muscular e ginástica para combater o estresse. O mesmo a culpa pelo seu estado que segundo ele seria por uma questão de escolha dela, bastava querer para mudar. Um claro exemplo do que falamos acima sobre o desconhecimento das implicações psicológicas no processo migratório, além da patologização do migrante. Aliado a isso, nos atendimentos ela por não falar japonês tinha de ser acompanhada do marido que fazia a tradução do que se passava com ela para o médico psiquiatra. Contudo, durante os atendimentos comigo muitas de suas questões giravam em torno da relação com o marido, ficando evidente, portanto a inadequação do mesmo como tradutor-intérprete nos atendimentos psiquiátricos. Vemos assim, que Marina não encontrara, até então, um lugar de acolhimento em que pudesse ser escutada, e sua história e seu momento, atravessados pela migração para o outro lado do mundo, compreendidos. Foi interessante notar que já nas primeiras semanas do atendimento intercultural ela relata melhora dos sintomas físicos.

Marina não é descendente, mas casada com um nipo-brasileiro o que segundo acordo bilateral entre Japão e Brasil permitia a entrada legal de

\footnotetext{
${ }^{23}$ DANTAS, Diálogos Interculturais..., op. cit.; FLORY, Elizabete. "Na outra língua se diz...": um estudo de caso sobre o falar bilíngüe.

${ }^{24}$ Cf. <http://www.ip.usp.br/laboratorios/intercult/>.

${ }^{25}$ Os nomes utilizados são fictícios a fim de preservar a identidade das mesmas.
} 
cônjuges de descendentes de japoneses no país. Apesar de formação profissional superior e já tendo exercido cargos de gerência no Brasil, com a mudança de país abre mão do trabalho e exerce os papéis de mãe e esposa enquanto o marido trabalha em uma fábrica, em condição inferior à sua qualificação. Através dos atendimentos, ela vai se dando conta do quanto assumiu o papel de 'Amélia'26 em sua vida. Apesar da diferença de fuso horário (ao atendê-la pela manhã no Brasil corresponde à noite no Japão) e do atendimento ser mediado pela tecnologia, no caso o aparelho telefônico, com o decorrer das sessões, sente-se compreendida, acolhida e vai sendo capaz de entender as conexões entre os cenários de sua vida. Volta a guiar, superando o medo com relação às diferenças da direção do automóvel (no Japão os carros são dirigidos do lado esquerdo com o volante do lado direito) e de normas mais rígidas de códigos de trânsito daquele país, vai à busca de um trabalho remunerado e aborda questões não ditas na família que vinha postergando. Progressivamente, torna-se autora de seu próprio script e vai se fortalecendo psicologicamente. Notamos o quanto esse processo intermediário possibilita a transição de um universo cultural a outro, o que lhe permite adentrar uma nova realidade cultural de forma ativa.

No caso de Andrea, brasileira residente na Alemanha, tanto ela quanto a terapeuta são brasileiras, bilíngues em português-alemão, sendo o alemão aprendido na idade adulta, ao viver na Alemanha. Conforme descrito por Flory ${ }^{27}$, os diálogos se davam em português e, em alguns momentos, a paciente utilizava termos em alemão. Andrea explica sua busca pelo atendimento por sentir "uma sensação de permanente inadequação, isolamento e ansiedade. (...) Sinto-me mais brasileira do que nunca. No Brasil eu era 'doutora'. Aqui sou apenas a Ausländerin que se mudou para a Alemanha". Naquele país ela vivencia o "ser estrangeira", "na própria pele" já há cerca de dois anos no país na ocasião. A terapeuta intercultural nota o uso da palavra alemã em uma fala em português. Entende que com isso denota contextos bem distintos. Ausländer apesar de significar estrangeiro, refere-se a pessoas que emigraram de países ditos em desenvolvimento, em busca de melhores condições de vida. Mas que tem uma conotação pejorativa em alemão, carregada de uma ideia do senso comum em que o estrangeiro é visto como uma ameaça ao emprego dos próprios alemães, ou seja, carregada de preconceito para com imigrantes.

$\mathrm{O}$ atendimento se faz mediado pela tecnologia e possibilita também o preparo de Andrea a uma visita para o Brasil em que iria rever sua família de origem. Uma família em que também não era reconhecida, vista como pessoa de valor e potencialidades. Durante sua estada no Brasil ela se encontra com a terapeuta e na volta para a Alemanha retoma o atendimento mediado pela

\footnotetext{
${ }^{26}$ Refere-se à letra do samba "Ai Que Saudades da Amélia", de Mário Lago e Ataulfo Alves em que a protagonista tornou-se sinônimo de mulher submissa.

27 FLORY, op. cit.
} 
tecnologia. Através da terapia Andrea vai podendo integrar aspectos de ambas as culturas com os quais se identifica, algo que se expressa em seu uso da língua, dizendo-se não mais uma Ausländerin, mas uma estrangeira naquele país.

\section{Orientação à distância e fenômenos transicionais}

Através desses dois casos buscamos ilustrar a suposição baseada em nossa experiência clínica, de que o atendimento e orientação intercultural online são ferramentas importantes no processo de inserção do migrante a um novo milleu cultural, funcionando como um espaço potencial que possibilita a transição do migrante de um universo cultural a outro, em que a tecnologia funciona como um objeto transicional. Importante ressaltar que nos baseamos no atendimento através da tecnologia no caso migratório, pautado em abordagem intercultural.

A teoria elaborada por Winnicott, psicanalista inglês que viveu de 1896 a 1971 trouxe uma série de formulações inovadoras para o exercício e o pensar psicanalítico. Através de seu trabalho como pediatra a observação da relação entre mães, cuidador/a e bebês, e trabalho com pacientes psicóticos ${ }^{28}$, formula uma teoria do desenvolvimento da natureza humana, do desenvolvimento emocional a partir da relação com o outro. Elabora uma teoria cujo enfoque na relação com o outro para a constituição do Eu e, portanto, da importância do ambiente, apresenta uma visão da questão psicológica profunda que contrasta com teorias mais tradicionais psicanalíticas em que o foco nas dinâmicas intrapsíquicas muitas vezes desconsidera o entorno da vida da pessoa, o impacto do mundo de relações. A relação com a mãe, ou cuidador, mostra-se assim de fundamental importância para a possibilidade de uma integração emocional e formação de sentimento de si, considerando-se inclusive o ambiente de relações em que a mãe ou cuidador/a está inserido. No processo de desenvolvimento humano, Winnicott concebe a relação de quem cuida do bebê, como sendo um ambiente facilitador para o outro vir a tornar-se uma pessoa separada, independente, a partir da experiência de dependência.

Como parte do processo de vir a ser, o autor descreve o uso por bebês de um objeto que seria uma primeira possessão de 'não-eu', através de uma sequência de atividades do bebê que começam em geral quando coloca o punho na boca e conduz a uma ligação a um ursinho, boneca, pano macio, ou mesmo o murmurar de uma melodia. Seria por meio dessas atividades que o bebê realizaria a transição entre seu mundo interno e externo. Esta seria a terceira parte da vida do ser humano, além do mundo interno e mundo externo. Constitui uma área intermediária de experimentação, para a qual contribuem tanto a

\footnotetext{
${ }^{28}$ A psicose designa um processo de deterioração em graus variáveis do contato com a realidade por parte da pessoa, diferente de estados psicóticos que abarcam um espectro amplo de quadros clínicos (ZIMERMAN, David. Vocabulário contemporâneo de psicanálise).
} 
realidade interna, o subjetivo, quanto a vida externa, o objetivamente percebido. Um estado intermediário entre uma inabilidade e habilidade em reconhecer e aceitar a realidade e que envolve a experiência da ilusão permitida ao bebê e que na vida adulta está entre a loucura e a arte ou religião. São os fenômenos transicionais que para o bebê são utilizados como defesa contra a ansiedade, como quando à noite, na hora de dormir, utiliza para se reconfortar um objeto macio, como a ponta de um cobertor, ou uma melodia, ou um maneirismo. A criança, assim, elege objetos que, paradoxalmente, são uma criação sua e algo que ele encontra no mundo (tendo uma materialidade que o objeto subjetivo não tinha). Objetos que não estão nem dentro nem fora, mas ocupam um espaço no qual estão, ao mesmo tempo, dentro e fora, unindo e separando o dentro e o fora. Eles dizem, pois, respeito a outra realidade que, por sua vez, ainda não é nem a realidade interna, nem externa, nem a subjetiva, mas um outro tipo de realidade, a transicional. Será o uso destes objetos, bem como uma série de outros acontecimentos, que caracterizará o processo de amadurecimento que criará as condições para que a realidade externa seja, enfim, reconhecida como tal, e ao mesmo tempo seja possível existir uma realidade interna diferenciada da externa ${ }^{29}$. Consiste "como lugar de repouso para o indivíduo empenhado na perpétua tarefa humana de manter as realidade interna e externa separadas, ainda que inter-relacionadas" ${ }^{\prime 30}$. A partir da possibilidade dessa experiência o autor formulara uma psicopatologia na área dos fenômenos transicionais. Fundamental será a possibilidade dessa experiência em que a mãe ou cuidador (e tudo que envolve a mesma) possam ser suficientemente bons no sentido de permitir essa vivência do espaço potencial que levará normalmente a uma descatexização gradativa do objeto transicional na medida que se desenvolvem os interesses culturais. "Não é o objeto, naturalmente, que é transicional. Ele representa a transição do bebê de um estado em que este está fundido com a mãe para um estado em que está em relação com ala como algo externo e separado"31.

Analogamente, a orientação intercultural através da tecnologia também não será mais necessária na medida em que a pessoa se insere na nova cultura, daí o papel preventivo da mesma conforme exposto acima. Contudo, enquanto possibilidade a orientação intercultural mediada pela tecnologia permite a instauração de um espaço potencial em que a realidade interna tingida de conteúdos da cultura originária pode ser compreendida diante o impacto que todo processo de inserção a uma nova realidade cultural externa supõe. E assim progressivamente a orientação intercultural mediada pela tecnologia, tendo cumprido seu papel transicional, chega a sua conclusão tendo possibilitado uma

\footnotetext{
${ }^{29}$ FULGÊNCIO, Leopoldo. Aspectos gerais da redescrição winnicottiana dos conceitos fundamentais da psicanálise freudiana.

${ }^{30}$ WINNICOTT, Donald W. O Brincar e a Realidade, p. 15.

31 Ibidem, p. 30.
} 
inserção mais consciente e pró-ativa do imigrante a seu novo milieu cultural. Uma inserção em que o contexto passado e presente são compreendidos, considerados e integrados à vivência da pessoa migrante.

\section{Considerações finais de momento}

Buscamos através desse artigo apontar para o papel preventivo em saúde mental da orientação e atendimento intercultural mediado pela tecnologia para as pessoas que migram de um espaço cultural a outro. Fizemos uma breve contextualização das migrações brasileiras, apresentamos estudos do uso da tecnologia pela psicologia no Brasil e exterior e nosso embasamento teórico. Dois casos de atendimentos realizados foram apresentados com o intuito de ilustrar a importância e efetividade do uso das mídias digitais (como a internet) em que o trabalho de orientação intercultural pode ter um importante papel na constituição de redes transnacionais para prevenção da saúde e sociabilidade nos deslocamentos migratórios. Relacionamos esse papel ao de um facilitador, criando assim um espaço potencial no sentido psicanalítico winnicottiano no processo de inserção do migrante a um novo ambiente cultural.

Cabe lembrar que esse papel é ainda mais importante no caso de países onde a saúde mental é considerada até os dias de hoje um tabu. Como exemplificado através de atendimento de brasileira residente no Japão, onde como em muitas outras culturas, distúrbios mentais são motivo de vergonha para família, vistos como refletindo um traço hereditário ou punição por ações erradas no passado da família e má orientação por parte do líder da família ${ }^{32}$. Assim, conceitos como saúde mental e cura são culturalmente engendrados e constituem parte da bagagem cultural de uma pessoa que se desloca e entra em contato com outra cultura, podendo agravar os entraves de sua nova inserção. Nesse sentido, se os países estivessem preparados com profissionais capacitados a partir de abordagem intercultural, poderiam oferecer este acolhimento. Cabe lembrar, portanto, que as implicações psicológicas da migração precisam ser conhecidas e respeitadas, afinal somos seres de cultura e de contato, é um direito que sejamos respeitados como tal.

\section{Bibliografia}

BAUMAN, Zygmunt. Globalização: as conseqüências humanas. São Paulo: Jorge Zahar Editor, 1999.

BLEGER, Jose. Psico-higiene e psicologia institucional. Porto Alegre: Artes Médicas, 1986.

BOTEGA, Tuíla; CAVALCANTI, Leonardo; OLIVEIRA, Antônio Tadeu (orgs.). Migrações Internacionais de Retorno no Brasil. Brasília: Relatório, 2015.

${ }^{32}$ DANTAS, Diálogos Interculturais..., op. cit. 
DANTAS, Sylvia. Subjetividade e migração: uma abordagem intercultural profunda a partir das migrações brasileiras. In GUANAES-LORENZI, Carla; MOTTA, Cibele Cunha Lima da; BORGES, Lucienne Martins; ZURBA, Magda do Canto; VECCHIA, Marcelo Dalla (orgs.). Psicologia Social e Saúde: da dimensão cultural à políticoinstitucional. Florianópolis: ABRAPSO, 2015, v. 2.

DANTAS, Sylvia. An intercultural psychodynamic counseling model. A preventive work proposition for plural societies. Counselling Psychology Quarterly, v. 24, 2011, p. 1-14.

DANTAS, Sylvia. Diálogos Interculturais: Reflexões interdisciplinares e intervenções psicossociais. Paulo: IEA-USP, 2012.

DANTAS, Sylvia. Nikkeis entre o Brasil e o Japão: desafios identitários, conflitos e estratégias. Revista USP, n. 79, 2008, p. 165-172.

DRAGUNS, Juris. Cross-cultural counseling and psychotherapy: History, issues, current status. In MARSELLA, Anthony; PEDERSON, Paul (eds.). Cross-cultural counseling and psychotherapy. New York: Pergamon Press, 1986.

FERREIRA, Ademir. A psicanálise no terreno do outro. In POVOA, Helion; FERREIRA, Ademir (orgs.). Cruzando fronteiras disciplinares. Rio de Janeiro: Editora Revan, FAPERJ, 2005.

FIORINI, Hector. Teorias e técnicas de psicoterapias. Rio de Janeiro: Livraria Francisco Alves Editora, 1985.

FLORY, Elizabete. "Na outra língua se diz...": um estudo de caso sobre o falar bilíngüe. In DANTAS, Sylvia (org.). Diálogos Interculturais: Reflexões interdisciplinares e intervenções psicossociais. São Paulo: IEA-USP, 2012.

FUSCO, William; SOUCHAD, Sylvain. De volta para casa: a distribuição dos brasileiros retornados do exterior. Confins, n. 9, 2010. Disponível em: < http://confins.revues. org/6469>.

FULGÊNCIO, Leopoldo. Aspectos gerais da redescrição winnicottiana dos conceitos fundamentais da psicanálise freudiana. Psicologia USP, São Paulo, v. 21, n. 1, 2010, p. 99-125.

MELLO, Patrícia Campos. Número de refugiados no Brasil quase dobra em quatro anos. Folha de São Paulo, 20.08.2015. Disponível em: <http://www1.folha.uol. com.br/mundo/2015/08/1671083-numero-de-refugiados-no-brasil-quase-dobraem-quatro-anos.shtml>.

NAKAGAWA, Fernando. Crise desperta desejo de migrar e brasileiros tentam emprego na Inglaterra e Japão. Estadão, 06.04.2015. Disponível em: < http://economia. estadao.com.br/blogs/fernando-nakagawa/crise-desperta-desejo-de-migrar-emais-pessoas-tentam-emprego-na-inglaterra-e-japao/>.

OSORIO, Luis Carlos. Novos paradigmas em psicoterapia. São Paulo: Casa do Psicólogo, 2006.

PIETA, Maria Adélia M.; GOMES, William B. Psicoterapia pela internet: Viável ou inviável? Ciência e Profissão, v. 34, n. 1, 2014, p. 18-31. 
PIETA, Maria Adélia M. Psicoterapia pela internet: a relação terapêutica. Tese doutorado. Programa de Pós-Graduação em Psicologia UFRGS, 2014.

PORTES, Alejandro; RUMBAUT, Rubén. Immigrant America: A Portrait. Berkeley, University of California Press, 1990.

SAM, David; BERRY, John. The Cambridge Handbbok on Acculturation Psychology. Cambridge: Cambridge University Press, 2006.

SARRIERA, José. Psicologia comunitária, estudos atuais. Porto Alegre: Editora Sulina, 2000.

ZIMERMAN, David. Vocabulário contemporâneo de psicanálise. Porto Alegre: Artmed, 2001.

WINNICOTT, Donald W. O Brincar e a Realidade. Rio de Janeiro: Imago, 1975.

\section{Abstract}

\section{Migration, mental health prevention, digital media}

The purpose of the present article is to argue for the preventive mental health role of psychological counseling and psychotherapy through technological mediation. It is based on research intervention carried on at two Brazilian universities. We have discovered the great benefit such technology may have on migration. Through study cases of Brazilians who were assisted through our research it is suggested that technology plays the role of a transitional object, in psychoanalytic terms, for those who move from one place to another in the world. Therefore, we argue that technology may be a tool of welfare promotion to those in mobility. In a world in which paradoxically as technology is improved its use in great measure has lead to increase social inequality including demonstrations of prejudice and xenophobia. In this article we indicate the use of technology as a measure of human rights in providing access to a dignified and meaningful life wherever one is.

Keywords: intercultural counseling, technology, mental health prevention.

Recebido para publicação em 15.03.2016

Aceito para publicação em 20.04.2016

Received for publication in March 15 $5^{\text {th }}, 2016$

Accepted for publication in April 20 th 2016

ISSN impresso 1980-8585

ISSN eletrônico 2237-9843

http://dx.doi.org/10.1590/1980-85852503880004610 